\title{
Pengaruh Permainan Beklen Biji Kopi terhadap Kemampuan Motorik Kasar pada Anak Usia 4-5 Tahun di Paud X Kota Bandung
}

\section{Rani Pratini*, Erhamwilda}

Prodi Pendidikan Guru PAUD, Fakultas Tarbiyah dan Keguruan, Universitas Islam Bandung, Indonesia.

*Raniapratini@gmail.com, Erhamhoernis@gmail.com

\begin{abstract}
Gross-motor ability activities of children are important things that must be considered in early children's growth. It is necessary to be developed because motor skills develop as well as children's maturity of the nerves and muscles. Based on the observation, the gross-motor skills of children (4-5 years old) at Permata Cendikia Early Childhood Education Programs are still lacking. This situation makes the researcher interested in giving a game for the students namely coffee bean jackstone (Bekel Biji Kopi) to improve their motor skills. The aim of this study is to determine the effect of the coffee bean jackstone on the gross-motor skills for 4-5 years olds at Bandung Permata Cendikia Early Childhood Education Programs. This study uses a quantitative method by using quasiexperimental design. It also uses a Non-equivalent Control Group Design where both groups are given pre-test and post-test, and only the experimental group is given special treatment. The sample of this study is a saturated sample where all 12 students at A-class are samples. Data collection techniques are implemented through observation and learning outcomes tests. The data analysis technique is an analysis test, it includes data description test, normality test, homogeneity test, balance test and hypothesis test. The results of data analysis and hypothesis test can be concluded that the formed value is sig coefficient (2-tailed), It is smaller $(0.05)$. Whereas HA is accepted and HO is rejected with an average comparison value 62.66 in the experimental class and 53.83 in the control class. It shows that there is an influence of the coffee bean jackstone game for 4-5 years olds' gross-motor skills at Bandung Permata Cendikia Early Childhood Education.
\end{abstract}

Keywords: Gross-Motor Ability, Coffee Bean jackstone Game, 4-5 years olds.

Abstrak. Gerakan tubuh yang harus diperhatikan bagi anak usia dini adalah pertumbuhan dan perkembangan gerak motorik kasar. Kemampuan motorik kasar sangat penting dikembangkan sejak anak usia dini, karena keterampilan motorik berkembang sejalan dengan kematangan syaraf dan otot anak. Berdasarkan pengamatan dilapangan, kemampuan motorik kasar anak 4-5 tahun di paud permata cendikia masih kurang, hal tersebut membuat peneliti tertarik untuk memberikan permainan menggunakan beklen biji kopi untuk membantu meningkatkan kemamuan motorik anak. Penelitian ini bertujuan untuk mengetahui pengaruh permainan beklen biji kopi terhadap kemampuan motorik kasar anak usia 4-5 tahun di Paud Permata Cendikia Kota Bandung.Metode yang digunakan dalam penelitian ini adalah metode kuantitatif dengan menggunakan rancangan metode Quasi Experimental Research atau eksperimen semu. jenis yang digunakan yaitu rancangan kelompok kontrol Pra Tes dan Pos Tes atau biasa disebut dengan Non-equivalent Control Group Design. Yang dimana pada kedua kelompok sama-sama dilakukan pre-test dan post-test, dan hanya kelompok eksperimen saja yang diberikan perlakuan atau treatment. Sampel penelitian ini adalah sampel jenuh, yang dimana semua anggota populasi di gunakan sebagai sampel, diantaranya seluruh anak usia 4-5 tahun yang berada dikelas kelompok A Paud permata Cendikia berjumlah 12 orang. Teknik pengumpulan data dengan tes hasil belajar dan observasi. Teknik analisi data yang digunakan adalah uji analis yang diantaranya uji deskripsi data, uji normalitas, uji homogenitas, uji keseimbangan dan uji hipotesis.Hasil analisis data dan pengujian hipotesis telah dilakukan maka dapat disimpulkan hasil perhitungan data menunjukan bahwa koefisien nilai sig (2-tailed) lebih kecil dari pada $\alpha(0,05)$ yang dimana Ha diterima dan Ho ditolak dengan perbandingan rata-rata dikelas eksperimen 62,66 dan rata-rata di kelas kontrol 53,83 yang artinya terdapat pengaruh permainan beklen biji kopi terhadap kemampuan motorik kasar anak usia 4-5 tahun di Paud Permata Cendikia Kota Bandung.

Kata Kunci: Kemampuan Motorik Kasar, Permainan Beklen Biji Kopi, Anak usia 4-5 tahun. 


\section{A. Pendahuluan}

Pembelajaran yang kita berikan untuk anak usia dini pada saat belum mengetahui tahapan pendidikan selanjutnya adalah satu usaha agar dapat memberikan pendidikan untuk anak ketika masih berada pada rentang usia prasekolah yaitu rentang umur 0-6 tahun, pemberian pendidikan bagi anak usia dini diterapkan dalam pemberian rangsangan pendidikan agar dapat membantu tumbuh kembang anak yaitu jasmani dan rohaninya. Yang dimana dalam pendidikan islam dikenal dengan sebutan istilah " Yaitu suatu pembelajaran yang kita berikan mulai dari anak-anak berumur o-6 tahun untuk menambah rangsangan kepada anak agar anak dalam pertambahan masa tubuh dan perubahan postur tubuh dan rohaninya setara sebagaimana mestinya, Supaya anak-anak mempunyai kecermatan dalam pembelajaran sehingga ketika mulai mendalami pembelajaran yang lebih lanjut dapat beradaptasi dengan baik.

Didalam islam seorang anak ialah amanah yang diberikan oleh Allah kepada setiap wali atau oranng tua, dimana mempunyai peran untuk selalu menjaga dan merawat sang buah hati karena anak adalah titipan yang diberikan sang pencipta kepada walinya, maka dari itu pendidikan untuk anak adalah sebuah kewajiban bagi walinya atau orangtua yang harus diberikan kepada anak sehingga hak seorang anak dapat terpenuhi, karena pada dasarnya setiap orang tua mempunyai peran penting terhadap semua hal yang dilakukan anak-anak mereka terutama dalam hal akhlak, dan wali atau orang tua mempunyai peran penting terhadap pendidikan anak, menjelmakan, membangun, membina, menumbuhkan dan membimbing sang buah hati mereka kepada arah tujuan yang disukai, dicintai dan diridhoi oleh RabbiAllah sangpencipta alam semesta. Yang dimana hal ini telah dijelaskan oleh rasulullah dalam hadist yang berbunyi:

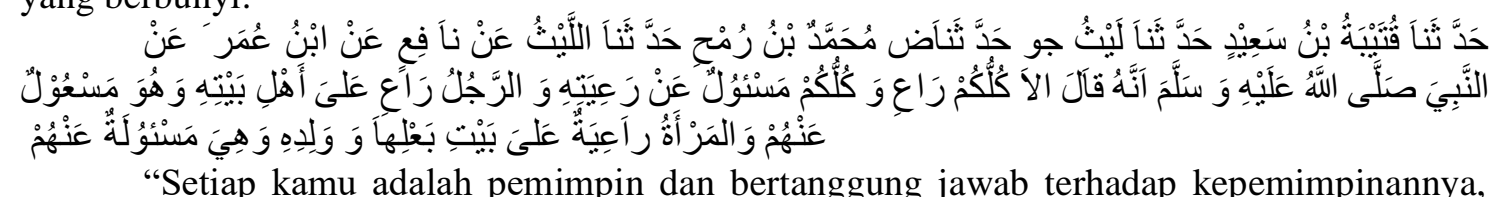
dan seorang laki-laki (Suami) adalah pemimpin atas keluarganya dan dianya bertanggung jawab atas keluarganya dan dianya bertanggung jawab atas yang dipimpinya dan seorang perempuan (istri) adalah pemimpin dirumah suami dan anak-anaknya dan ia bertanggung jawab terhadap kepemimpinannya (H.R. Bukhori, Muslim dan Tirmidzi). Makna dari hadist diatas Rasulullah mengungkapkan bahwa kewajiban atau tanggungan dalam pendidikan anak secara keseluruhan adalah tanggung jawab orangtuanya, tanggung jawab orangtua kepada sangbuah hati wajib diberikan secara sungguhsungguh mulai dari buah hati lahir, diberikan pembelajaran yang dimana harus didasari oleh keimanan yang sempurna dan akidah yan betul adanya, syariat, dan juga akhlakulkarimah yang paling penting. (Syafrida siregar, 2016)

Pendidikan formal bagi siswa usia dini dibagi sesuai rentang umur siswa yaitu mulai dari 4-5 tahun bagi kelompok A dan 5-6 tahun bagi kelompok B. Sebagaimana pada masa pertumbuhan ini sering dikenal dengan zaman kejayaan atau kekemasan sehingga sering diingat sebagai masa Golden Age, di mana pada saat ini perkembangan otak anak mengalami perubahan dan peningkatan perkembangan yang sangat cepat selama perjalanan hidupnya. Masa berkembanganya kehidupan manusia dimulai dan diawali oleh pertumbuhan dan perkembangan anak mulai dari usia dini yang berlangsung dari usia lahir hingga enam tahun (Murian, 2018). Saat anak mengalami masa keemasan dalam kehidupannya anak akan mempunyai peran yang sangat penting bagi setiap perkembangannya sendiri, ia akan mengalami sebuah perubahan diri mulai dari pertumbuhan tubuh dan perkembangan pesat dalam setiap aspek perkembangan. (Masnipal, 2018).

Motorik kasar adalah suatu pergerakan dan perubahan bagian tubuh yang memfungsikan otot-otot besar, atau seluruh aggota tubuh, yang dapat disebabkan oleh usia, berat badan dan pertumbuhan anak secara fisik. Contohnya yaitu pada kemampuan gerak tubuh seperti menggenggam, menendang benda, naikturun tangga dan duduk. Kemampuan motorik kasar pada anak sangatlah penting karena sebagai modal utama untuk meraih setiap keahlian atau kemampuan selanjutnya yaitu motorik halus.(Novitasari et al., 2019) menyatakan bahwa gerakan motorik kasar ialah suatu gerak tubuh yang memfungsikan setiap anggota tubuh 
pengaruh dari kematangan anak dalam aspek perkembanagn anak itu sendiri. Kemampuan motorik kasar menurut Gallahue dalam (Nisa monicha, 2020) ialah aplikasi otot-otot besar dalam melakukan beberapa gerakan, seperti gerakan lokomotor yang terdiri dari berlari, meloncat, melompat, mendorong, keterampilan-keterampilan yang manipulatif seperti menarik menggunakan tanggan, melempar dan menggabungkan bola, mengambil bola, menendang, melempar sambil mengayun-ayunkan tangan hingga tinggi, berkeliling dengan perlahan ataupun cepat, dan beberapa elemen kemampuan motorik kasar.

Bermain adalah sebuah kegiatan aktivitas yang menggembirakan bagi anak, bermain adalah aktivitas rekreasi yang mempunyai sebuah tujuan meningkatkan hormon endorfin yaitu rasa senang dan bahagia bagi anak untuk memenuhi waktu yang kosong. Permainan biasanya dapat dilakukan sendiri atau bersama-sama dengan kawan sejawat, menggunakan alat atau tidak menggunakan alat. Sedangkan yang dimaksud dengan permainan tradisional adalah permainan yang dilakukan secara turun temurun dari orang tua atau nenek moyang, permainan tradisional juga dianggap oleh sebagian orang permainan yang diwarisi dari satu generasi ke generasi yang lainnya. Permainan tradisional mempunyai konsep permainan yang sederhana dan tanpa disadari dapat menjadi sarana untuk meningkatkan kemampuan anak, salah satunya permainan beklen, permainan beklen ialah sebuah permainan tradisional yang memfokuskan pada perkembangan gerak tubuh anak yang dibantu dengan alat bola kecil yang terbuat dari karet dan buji-bijian yang dimana dikenal dengan kuwuk beklen. Nama beklen sendiri diperkirakan berasal dari bahasa belanda yaitu bikkelen artinya pantang menyerah untuk berjuang. Permainan tradisional memiliki konsep permainan yang sederhana tetapi mengasikkan bagi anak (Hasana Alfianur, 2016).

Sesuai dengan hasil pengamatan awal yang dilaksanakan peneliti di Paud Permata Cendikia Kota Bandung pada hari senin 28 maret 2021 menunjukkan bahwa dalam mengembangkan kemampuan motorik kasar guru melaksanakan kegiatan pembelajaran dengan menggunakan beberapa permainan yang diantaranya adalah permainan gobak sodor, sondah dan bermain bola, yang mengakibatkan permainan cenderung berulang dan monoton sehinga ditemukan beberapa masalah pada anggota siswa kelompok A di paud permata cendikia yaitu pada aspek fisik motorik kasar, yang mana dapat diketahui bahwa kemampuan motorik kasar anak didik berada pada kategori Berkembang Sangat Baik (BSB) sebanyak 1 orang dengan peresntase 10\%, Pada kategori Berkembang Sesuai Harapan (BSH) sebanyak 2 orang dengan persentase 20\%, anak yang berada pada kategori Mulai Berkembang (MB) sebanyak 7 orang dengan persentase 50\%, dan anak dengan kategori Belum Berkembang (BB) sebanyak 2 orang dengan persentase $20 \%$. Di dalam kelas terdapat sepuluh anak yang cenderung belum sepenuhnya melakukan gerakan motorik kasar yang terkoordinasi dengan baik. semua ini terlihat pada beberapa kegiatan belajar dalam kelas bersama guru. Salah satunya ketika bermain menendang sesuatu dengan terarah dan melakukan gerakan antisipasi dalam permainan. Anakanak yang belum bisa harus di berikan arahan berkali-kali agar dapat melakukan dengan baik. Setiap anak perlu adanya peningkatan ketangkasan gerak tubuhnya, maka hendaknya guru dapat menciptakan sebuah strategi yang tepat dalam membantu anak untuk menumbuhkan keahlian fisik motorik kasar. Diantaranya ialah sebuah sarana bermain, yang dimana bermain memberikan efek senang dan gembira pada anak sehingga pada saat bermain imajinasi anak akan terbentuk dengan sendirinya dan menghasilkan sebuah pengertian, pemahaman, dan menjadi seumber informasi bagi anak tanpa menggunakan alat permainan. Pemilihan media atau permainan yang digunakan oleh pendidik harus menarik, kreatif, tidak membosankan dan melibatkan anak didik agar anak lebih aktif dalam pembelajaran khususnya dalam meningkatkan motorik kasar anak.Menurut Standar Tingkat Pencapaian Perkembangan Anak untuk usia 4-5 tahun anak dapat melakukan gerakan meniru binatang, pohon yang tertiup angin, pesawat yang terbang tinggi dan rendah, melakukan gerakan menggelantung, gerakan meloncat, dan berlari secara terkoordinasi, melempar sesuatu secara terarah, menangkap sesuatu secara tepat, melakukan gerakan antisipasi, menendang sesuatu secara terarah, dan memanfaatkan alat permainan diluar ruangan secara tepat.

Berdasarkan latar belakang yang telah diuraikan diatas, maka dalam penelitian ini mempunyai tujuan penelitian yang diantaranya adalah: 
1. Menukur kemampuan motorik kasar pada anak usia 4-5 tahun di Paud Permata Cendikia Kota Bandung sebelum melakukan permainan beklen biji kopi.

2. Mengetahui cara pelaksanaan permainan beklen biji kopi pada anak usia 4-5 tahun di Paud Permata Cendikia Kota Bandung

3. Mengetahuikemampuan motorik kasar pada anak usia 4-5 tahun di Paud Permata Cendikia Kota Bandung

4. Mengetahui perbandingan beda yang tinggi terhadap perkembangan motorik kasar dari sebelum dan sesudah permainan beklen biji kopi.

\section{B. Metodologi Penelitian}

Pendekatan kuantitatif adalah pendekatan yang dilaksanakan saat penelitian ini, menurut (Creswell, 2019) pendekatan kuantitatif ialah suatu pendekatan yang saling berkaitan mengenai variabel devinisi dan proposisi untuk menunjukkandan menjelaskan fenomena alamiyah. dengan rancangan metode Quasi Experimental Research atau eksperimen semu. Yang dimana merupakan teknik suatu penelitian harus mempunyai kelompok kontrol dan kelompok eksperimen yang dipilih tidak secara acak atau random sesuai dengan jenis yang digunakan yaitu rancangan kelompok kontrol pretest dan postest atau biasa disebut dengan Non-equivalent Control Group Design. Yaitu pada setiap kelompok sama-sama melakukan pretest dan posttest, tetapi untuk kelompok eksperimen saja yang diberlakukan perlakuan atau treatmean.

\section{Hasil Penelitian dan Pembahasan}

Berdasarkan penelitian yang dilakukan di paud permata cendikia Kota Bandung saat semester genap tahun ajaran 2020/2021 menggunakan pengaruh permainan beklen biji kopi terhadap kemampuan motorik kasar pada anak usia 4-5 tahun di Paud Permata Cendikia Kota Bandung terdapat kelompok A yang memiliki jumlah siswa Dua belas orang yang terdiri dari tujuh anak perempuan dan lima anak laki-laki kemudian dalam melakukan penelitian ini sampel yang dipakai adalah seluruh anak kelompok A yang berjumlah 12 Orang dimana anak dibagi menjadi kelompok kontrol dan kelompok eksperimen. Pelaksanaan melakukan protokol kesehatan. Pengambilan data dilakukan dengan cara home visit yang dimana anak di datangi ke rumah mereka, apabila jarak rumah mereka berdekatan maka anak akan datang ke rumah temannya, sehingga jarak anak ke tempat belajar tidak terlalu jauh, dan untuk pembelajaran anak di bagi menjadi dua sesi yang dimana peserta didik berjumlah 6 siswa baik putra maupun putri sehingga anak dapat menjaga jarak di dalam ruangannya. Kemudian peneliti melakukan kegiatan yang melatih beberapa aspek perkembangan yang dimana untuk aspek perkembangan motorik kasar peserta didik diajak untuk melakukan permainan beklen biji kopi. Setelah kegiatan selesai, peneliti mengisi lembar pengamatan penelitian sebagai penilaian terhadap kemampuan motorik kasar anak usia 4-5 tahun di Paud Permata Cendikia

Kota Bandung. Adapun hasil penelitian dari penelitian terhadap kemampuan motorik kasar anak usia 4-5 tahun di Paud Permata Cendikia Kota Bandung sebagai berikut:

1. Kecakapan siswa sebelum menggunakan kegiatan bermain beklen biji kopi pada kelompok eksperimen.

Tabel 1. Penelitian Kecakapan Siswa Sebelum Menggunakan Kegiatan Bermain Beklen Biji Kopi pada Kelompok Eksperimen

\begin{tabular}{|c|c|c|c|c|c|c|c|}
\hline \multirow{2}{*}{ NAMA } & \multicolumn{4}{|c|}{ PENILAIAN } & \multirow{2}{*}{$\begin{array}{l}\text { TOTAL } \\
\text { SKOR } \\
\end{array}$} & \multirow{2}{*}{$\%$} & \multirow{2}{*}{ KET } \\
\hline & BB & MB & BSH & BSB & & & \\
\hline 1 & 7 & 5 & 8 & 0 & 41 & $51 \%$ & BSH \\
\hline 2 & 0 & 0 & 8 & 12 & 72 & $90 \%$ & BSB \\
\hline 3 & 10 & 10 & 0 & 0 & 30 & $38 \%$ & $\mathrm{MB}$ \\
\hline 4 & 1 & 9 & 3 & 7 & 56 & $70 \%$ & $\mathrm{BSH}$ \\
\hline 5 & 15 & 5 & 0 & 0 & 25 & $31 \%$ & $\mathrm{MB}$ \\
\hline 6 & 8 & 7 & 5 & 0 & 37 & $46 \%$ & $\mathrm{MB}$ \\
\hline
\end{tabular}


Berdasarkan tabel yang dijelaskan diatas, diperoleh temuan penelitian bahwa dari 6 anak menggunakan 20 butir instrumen penelitian, diperoleh hasil penelitian pretest penelitian kemampuan motorik kasar pada kelas eksperimen dengan kategori Belum Berkembang(BB) tidak ada, Mulai Berkembang (MB) 3 orang anak, berkembang sesuai harapan (BSH) sebanyak 2 orang anak dan Berkembang Sangat Baik 1 Orang anak. Sedangkan berdasarkan data statistik dijelaskan bahwa nilai pretest kelompok eksperimen adalah nilai terendah 25, nilai tertinggi 73, nilai rata-rata 43,66 dan nilai simpang baku 17.73. sedangkan untuk kemampuan motorik kasar untuk kelompok kontrol hasil observasi awalnya sebagai berikut:

Tabel 2. Kemampuan Motorik Kasar untuk Kelompok Kontrol

\begin{tabular}{|c|c|c|c|c|c|c|c|}
\hline \multirow{2}{*}{ NAMA } & \multicolumn{4}{|c|}{ PENILAIAN } & \multirow{2}{*}{$\begin{array}{c}\text { TOTAL } \\
\text { SKOR } \\
\end{array}$} & \multirow{2}{*}{$\%$} & \multirow{2}{*}{$\begin{array}{l}\text { KETER } \\
\text { ANGAN } \\
\end{array}$} \\
\hline & BB & MB & BSH & BSB & & & \\
\hline 1 & 0 & 8 & 9 & 3 & 55 & $69 \%$ & $\mathrm{BSH}$ \\
\hline 2 & 7 & 13 & 0 & 0 & 33 & $41 \%$ & $\mathrm{MB}$ \\
\hline 3 & 6 & 14 & 0 & 0 & 34 & $43 \%$ & $\mathrm{MB}$ \\
\hline 4 & 5 & 7 & 8 & 0 & 43 & $54 \%$ & $\mathrm{BSH}$ \\
\hline 5 & 0 & 5 & 12 & 3 & 58 & $73 \%$ & $\mathrm{BSH}$ \\
\hline 6 & 3 & 8 & 4 & 5 & 51 & $64 \%$ & $\mathrm{BSH}$ \\
\hline
\end{tabular}

Berdasarkan tabel diatas dapat disimpulkan bahwa kemampuan motorik anak dari 6 anak menggunakan 20 butir instrumen penelitian, diperoleh hasil penelitian pretes pada kelompok kontrol anak yang perkembangannya Mulai Berkembang (MB) ada 2 orang anak dan anak yang perkembanganya Berkembang Sesuai Harapan (BSH) ada 4 orang anak. Sedangkan dalam perhitungan statistik deskriptif hasil data yang diperoleh adalah nilai terendah 33, nilai tertinggi 58 dan nilai rata-rata 46,16 dan nilai simpang baku 10,70.

2. Kemampuan motorik kasar anak sesudah melakukan permainan beklen biji kopi.pada kelompok eksperimen dijelaskan dalam tabel berikut:

Tabel 3. Kemampuan Motorik Kasar Anak Sesudah Melakukan Permainan Beklen Biji Kopi pada Kelompok Eksperimen

\begin{tabular}{|c|c|c|c|c|c|c|c|}
\hline \multirow{2}{*}{ NAMA } & \multicolumn{4}{|c|}{ PENILAIAN } & \multirow{2}{*}{$\begin{array}{c}\text { TOTAL } \\
\text { SKOR }\end{array}$} & \multirow{2}{*}{$\%$} & \multirow{2}{*}{$\begin{array}{l}\text { KETER } \\
\text { ANGAN }\end{array}$} \\
\hline & $\mathrm{BB}$ & MB & BSH & BSB & & & \\
\hline 1 & 0 & 4 & 12 & 4 & 60 & $75 \%$ & BSH \\
\hline 2 & 0 & 1 & 6 & 12 & 73 & $91 \%$ & BSB \\
\hline 3 & 0 & 6 & 14 & 0 & 54 & $68 \%$ & $\mathrm{BSH}$ \\
\hline 4 & 0 & 2 & 13 & 5 & 63 & $79 \%$ & BSB \\
\hline 5 & 0 & 5 & 6 & 9 & 64 & $80 \%$ & BSB \\
\hline 6 & 0 & 4 & 10 & 6 & 62 & $78 \%$ & BSB \\
\hline
\end{tabular}

Berdasarkan tabel yang dijelaskan diatas, diperoleh temuan penelitian bahwa 6 anam menggunakan 20 butir instrumen penelitian, maka penelitian kemampuan motorik kasar mempunyai hasil posttest kelompok eksperimen dengan kategori Berkembang Sesuai harapan (BSH) 2 orang anak dan Berkembang Sangat Baik 4 orang anak. Sedangkan dalam perhitungan statistik deskriptif hasil yang diperoleh dari kelompok eksperimen untukk nilai terendah 54, nilai tertinggi 73 , nilai rata-rata 62,66 dan nilai simpang baku 6,18. Sedangkan untuk kemampuan motorik kasar untuk kelompok kontrol hasil observasi akhirnya adalah sebagai berikut:

Tabel 4. Kemampuan Motorik Kasar untuk Kelompok Kontrol

\begin{tabular}{|c|c|c|c|c|c|c|c|}
\hline \multirow{2}{*}{ NAMA } & \multicolumn{4}{|c|}{ PENILAIAN } & \multirow{2}{*}{$\begin{array}{c}\text { TOTAL } \\
\text { SKOR } \\
\end{array}$} & \multirow{2}{*}{$\%$} & \multirow{2}{*}{$\begin{array}{l}\text { KETER } \\
\text { ANGAN }\end{array}$} \\
\hline & BB & MB & BSH & BSB & & & \\
\hline 1 & 0 & 7 & 9 & 4 & 57 & $71 \%$ & BSH \\
\hline 2 & 0 & 12 & 8 & 0 & 48 & $60 \%$ & BSH \\
\hline 3 & 0 & 10 & 9 & 1 & 51 & $64 \%$ & BSH \\
\hline 4 & 0 & 10 & 9 & 1 & 51 & $64 \%$ & BSH \\
\hline 5 & 0 & 4 & 13 & 3 & 59 & $74 \%$ & BSH \\
\hline 6 & 0 & 6 & 11 & 3 & 57 & $71 \%$ & BSH \\
\hline
\end{tabular}


Berdasarkan tabel yang ada dapat dijelaskan bahwa keseluruhan kelompok kontrol setelah 6 anak menggunakan 20 butir instrumen penelitian, hasil dari penelitian kemampuan motorik kasar setelah melakukan postest pada kelompok kontrol dengan kategori Berkembang Sesuai Harapan (BSH) sebanyak 6 orang anak, hal ini dijelaskan dalam statistik deskriptif nilai terendah 48 , nilai tertinggi 59, nilai rata-rata 53,83, dan nilai simpang baku 4,40.

1. Uji Normalitas

Uji ini dilakukan agar dapat mengetahui kondisi data mempunyai distribusi normal atau tidak, yang dimana data yang berdistribusi normal adalah syarat untuk menemukan uji $t$ yang dipakai. Dalam pembuatan data hasil pengujian normalitas menggunakan sebuah desain strategi SPSS versi 20.00 for window dengan uji shapirow-wilk karena menggunakan sampel yang kecil. Dengan hasil data pretest kelompok eksperimen berdistribusi normal, yang dibuktikan dengan adanya koefisien sig kolmogrov smirnov sebesar 0,200 dan shapiro wilk 0,583 yang kesemuanya $>0,05$. Dan data pretest kelompok kontrol berdistribusi normal, dibuktikan dengan adanya koefisien sig kolmogrov smirnov sebesar 0,200 dan shapiro wilk 0,374 yang kesemuanya >0,05. Sedangan pada postest kelompok eksperimen berdistribusi normal, dibuktikan dengan koefisien sig kolmogrov smirnov sebesar 0,200 dan shapiro wilk 0,678 yang kesemuanya $>0,05$. Dan pada kelompok kontrol setelah postest ditemukan hasil data yang normal, dibuktikan dengan koefisien sig kolmogrov smirnov sebesar 0,200 dan shapiro wilk sebesar 0,321 yang kesemuanya $>0,05$.

2. Uji Homogenitas

Uji Homogenitas dilakukan untuk mengetahui sebuah variansi sampel dari populasi yang sama, yang dimana dalam penelitian ini uji homogenitas dilakukan data pretest eksperimen dan kontrol, serta data postest eksperimen dan kontol yang dilakukan dengan menggunakan uji Laven's test dengan koefisien sig besar dari 0,05 sehingga akan mendapatkan hasil variansi yang homogen, yang dijelaskan dalam tabel berikut:

Tabel 5. Independent Samples Test

\begin{tabular}{|c|c|c|}
\hline \multirow{2}{*}{} & \multicolumn{2}{|c|}{$\begin{array}{c}\text { Levene's Test For Equality of } \\
\text { Variances }\end{array}$} \\
\cline { 2 - 3 } & F & Sig. \\
\hline Pretest Equal Variances assumed & 1.291 & .282 \\
\hline
\end{tabular}

Berdasrkan tabel diatas dapat dijelaskan bahwa hasil pengujian kelompok pretest, diperoleh temuan penelitian bahwa kelompok data pretest eksperimen dan kontrol mempunyai hasil yang homogen yang dibuktikan dengan, koefisien sig sebesar 0,282 >0,05.

Tabel 6. Independent Samples Test

\begin{tabular}{|c|c|c|}
\hline \multirow{2}{*}{} & $\begin{array}{c}\text { Levene's Test For } \\
\text { Equality of } \\
\text { Variances }\end{array}$ \\
\cline { 2 - 3 } & F & Sig. \\
\hline $\begin{array}{c}\text { Postest Equal } \\
\text { Variances assumed }\end{array}$ & .008 & .930 \\
\hline
\end{tabular}

Berdasarkan tabel diatas dapat dijelaskan bahwa hasil dari uji kelompok posttest, diperoleh temuan penelitian bahwa kelompok data postest eksperimen dan kontrol mempunyai hasil yang homogen, dibuktikan dengan koefisien sig sebesar 0,930>0,05. 
1. Uji keseimbangan

Pengujian ini dilakukan agar dapat mengetahui dua rataan kelas eksperimen dengan uji persyaratan analisis pada sampel harus dari populasi berkontribusi normal dan homogen. Dalam uji keseimbangan statistik yang digunakan adalah uji $\mathrm{F}$ pada tingkatan signifikansi alpa 0,05. Berdasarkan uji pretest kedua kelas yaitu kelompok kontrol dan kelompok eksperimen mempunyai kemampuan awal yang sama dengan menggunakan bukti koefesien sig 0,802>0,05.

2. Uji Hipotesis

Uji Hipotesis ini dilakukan agar dapat mengetahui apakah hipotesis yang dilakukan dalam penelitian ini diterima atau ditolak, yang dimana pengajuan hipotesis dengan menggunakan teknik uji statistik sehingga akan menghasilkan distribusi yang cocok.

Tabel 7. Independen Sample Test

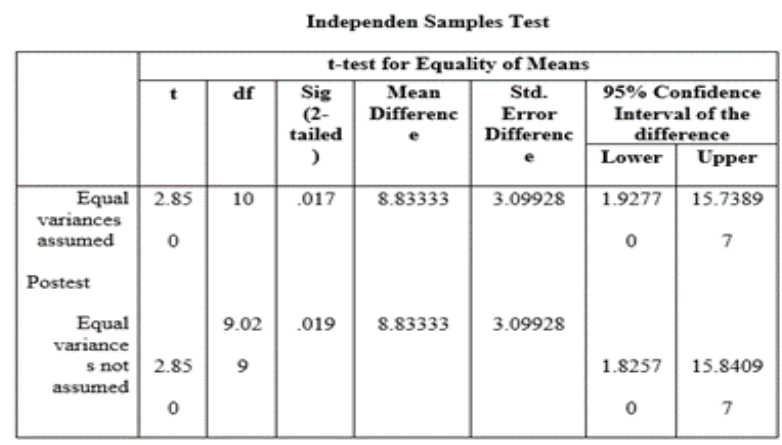

Berdasarkan tabel yang dijelaskan diatas, memperoleh temuan bahwa terdapat perbedaan pengaruh dalam pemberian perlakuan permainan beklen biji kopi terhadap kemampuan motorik kasar pada kelompok eksperimen dan kelompok kontrol maka dilakukan uji independen sampel t-test pada postest kelompok eksperimen dan kelompok kontrol, dengan kaidah koefesien sig $<0,05$ sehingga bisa disimpulkan bahwa Ho ditolak dan Ha diterima karena terdapat perbedaan yang signifikan antara pengaruh permainan beklen biji kopi. Terhadap kemampuan motorik kasar anak usia 4-5 tahun di paud Permata Cendikia Kota Bandung.

Penelitian ini dilaksanakan agar dapat mengetahui kemampuan motorik kasar pada anak usia 4-5 tahun di paud permata cendikia kota Bandung yang dimana anak sebelumnya tidak pernah melakukan kegiatan motorik kasar dengan menggunakan beklen biji kopi, proses pelaksanaan penelitian ini dilakukan pada saat pandemi covid-19, sehingga dalam penelitian ini setiap anak dan pengajar harus menggunakan protokol kesehatan agar keberlangsungan penelitian ini dapat dilakukan dengan lancar, tanpa adanya hambatan yang mengganggu. Dalam penelitian ini diketahui bahwa perkembangan motorik anak saat belum melakukan permainan beklen biji kopi masih kurang,hal itu dikarenakan permainan permainan motorik kasar disekolah masih monoton.

Hasil dari penelitian ini adalah dengan adanya permainan yang menarik maka anak dengan senang hati akan melakukan gerakan-gerakan kecil sehingga tanpa disadari oleh dirinya itu akan meningkatkan perkembangan motorik kasarnya, dengan mengenal permaian tradisonal khususnya modifikasi beklen biji kopi, maka anak akan mengembangakan motorik kasarnya, terutama pada gerakan tanggan, ketangkasan, kecermatan, koordinasi anggota tubuh, dan dengan aroma kopi pula anak akan menjadi fokus.

\section{Kesimpulan}

Setelah mengetahui hasil pembahasan dari prosedur penelitian ini maka peneliti dapat memberikan kesimpulan yang diantaranya ialah:

1. Kemampuan motorik kasar pada anak usia 4-5 tahun di Paud Permata Cendikia sebelum menggunakan permainan beklen biji kopi terlihat dari perkembangan anak pada kelompok kontrol siswa pada kategori mulai berkembang 2 orang, dan berkembang 
sesuai harapan 4 orang, sedangkan pada kelompok eksperimen anak yang mulai berkembang sebanyak 3 orang anak, berkembang sesuai harapn 2 orang dan berkembang sangat baik 1 orang anak.

2. Pelaksanaan permainan beklen biji kopi pada anak usia 4-5 tahun di Paud Permata Cendikia dilakukan dengan menerapkan protokol kesehatan untuk mencegah penyebaran covid-19, anak memainkan permainan ini dengan berjarak antar anak, sehingga tidak berdekatan, permainan ini menggunakan bola beklen yang berukuran kecil dan terbut dari bahan karen sehingga memudahkan melempar saat di pantulkan, dan menggunakan biji kopi yang berjumlah 6 biji.

3. Peningkatan motorik kasar pada anak usia 4-5 tahun di Paud Permata Cendikia sesudah menggunakan permainan beklen biji kopi terlihat dari perkembangan anak setelah menggunakan instrumen penelitian, peneliti melakukan postest kepada kelompok eksperimen dan kelompok kontrol sehingga dapat dilihat nilai perkembangan motorik kasar anak setelah melakukan postest yang dimana pada kelompok eksperimen diberikan treatmen permainan beklen biji kopi dan pada kelompok kontrol diberikan permainan reguler tanpa menggunakan permainan beklen biji kopi. Sehingga menghasilkan peningkatan pada kelompok eksperimen terlihat dari anak yang Berkembang Sesuai Harapan (BSH) ada 2 orang dan Berkembang Sangat Baik (BSB) ada 4 orang anak, sedangkan pada kelompok kontrol anak yang Berkembang Sesuai Harapan (BSH) ada 6 orang anak dan Berkembang Sangat Baik tidak ada, sehingga dengan adanya permainan beklen biji kopi perkembangan anak pada kelompok eksperimen lebih baik dari kelompok kontrol.

4. Terdapat Perbedaan yang signifikan perkembangan motorik kasar antara sebelum dan sesudah permainan beklen biji kopi, yang dimana dibuktikan dengan kemampuan motorik anak pada kelompok eksperimen lebih tinggi ketika dibandingkan dengan nilai kemampuan motorik kelompok kontrol sebagaimana dijelaskan bahwa nilai rata-rata 62,66 pada kelompok eksperimen sedangkan pada kelompok kontrol 53,83. Nilai ratarata ini didaptkan dengan menggunakan lembar instrumen kemampuan motorik kasar anak yang diajarkan menggunakan permainan beklen biji kopi lebih baik dibandingkan dengananak-anak kelompok kontrol yang tidak menggunakan permainan ini.

\section{Acknowledge}

Rasa syukur yang terdalam penulis panjatkan kepada khadirat Allah SWT yang sudah memberikan pengetahuan, keteguhan hati dalam menuntaskan penyelesaian penelitian ini. Saat melakukan penulisan karya tulis ini penulis sangat banyak mendapatkan pertolongan dan tuntunan dari segala pihak, sehingga penulis sangat ingin menyampaikan banyak trimakasih kepada:

1. Allah SWT , tuhan semesta alam yang telah menciptakan manusia beserta seluruh kemampuan-kemampuannya.

2. Prof.Dr.H.Edi Setiadi., S.H.,M.H, selaku Rektor Universitas Islam Bandung sebagaimana sudah memberi berbagai fasilitas dan kesempatan kepada penulis untuk melanjutkan studi di Universitas Islam Bandung.

3. Bapak Enoh Drs.M.Ag, Deken Fakultas Tarbiyah dan Keguruan Universitas Islam Bandung yang telah memberikan izin dalam penyususan penelitian ini.

4. Ibu Dr.Erhamwilda,D.ra.,M.Pd Ketua Jurusan Pendidikan Guru Pendidikan Anak Usia Dini Universitas Islam Bandung.

5. Ibu Dr. Erhamwilda., sebagai pembimbing I Dra.,M.Pd dan Ibu Nurul Afrianti, M.Pd.,M.Si.Psi. sebagai pembimbing II yang telah membimbing dengan penuh kesabaran dan mengarahkan penulis untuk menyelesaikan studi ini.

Seluruh dosen Fakultas Tarbiyah Keguruan khususnya Prodi PG PAUD yang telah memberikan segenap ilmunya untuk pendidikan dan pembelajaran kepada penulis, semasa menimba ilmu di fakultas Tarbiyah dan Keguruan Universitas Islam Bandung. 


\section{Daftar Pustaka}

[1] Creswell, J. W. (2019). Research Design Pendekatan Metode Kualitatif, Kuantitatif dan Campuran (Edisi Baha). Pustaka Pelajar.

[2] Hasana Alfianur, L. (2016). Pengaruh permainan tradisional ( bekelan dan slentikan) terhadap peningkatan kemampuan problem solving anak usia sekolah skripsi. file:///F:/reverensi proposal up/pengaruh permainan tradisional beklen.pdf

[3] Masnipal, M. (2018). Menjadi Guru PAUD Profesional. Remaja Rosda Karya.

[4] Murian, O. (2018). Usia Dini 4-5 Tahun Melalui Gerakan-Gerakan Lampung 1440 H / 2018 Mengembangkan Kemampuan Motorik Kasar Anak Usia Dini 4-5 Tahun Melalui GerakanGerakan.

[5] Nisa monicha. (2020). Peningkatan Kemampuan Motorik Kasar Melalui Permainan Sirkuit. Jurnal Cikal Cendikia,PG PAUD Universitas PGRI, O1(01), 33-42.

[6] Novitasari, R., Nasirun, M., \& D., D. (2019). Meningkatkan Kemampuan Motorik Kasar Anak Melalui Bermain Dengan Media Hulahoop Pada Anak Kelompok B Paud Al-Syafaqoh Kabupaten Rejang Lebong. Jurnal Ilmiah POTENSIA, 4(1), 6-12. https://doi.org/10.33369/jip.4.1.6-12

[7] Syafrida siregar, L. Y. (2016). Pendidikan Anak Usia Dini Dalam Prespektif Islam. JCE (Journal of Childhood Education), 1(1), 56-67. https://doi.org/10.30736/jce.v1i1.6 